\title{
Kinetic and thermodynamic control in assembly of rare-earth cyamelurates
}

\author{
A. Isbjakowa, V. Chernyshev, V. Tafeenko, L. Aslanov \\ Moscow State University, Leninskie Gory 1, Moscow, 119991, Russian Federation \\ albinabushmeleva@mail.ru
}

Kinetic control is an upcoming method for producing a wide variety of desired functional structures [1,2]. Thermodynamic assembly allows the reaction system to achieve equilibrium, thus forming thermodynamically stable compounds, whereas kinetic assembly traps metastable states via fast crystallization at low temperatures and at high concentrations. However, rapid crystallization causes difficulties with $a b$ initio structure determination by X-ray diffraction, since the main products are crystalline powders rather than single crystals $[1,3]$.

We found that in the row of rare-earth cyamelurates three structural types exist. Room temperature synthesis $\left(22-25^{\circ} \mathrm{C}\right)$ leads to the formation of compounds $\left[\mathrm{M}\left(\mathrm{H}_{2} \mathrm{O}\right)_{7} \mathrm{C}_{6} \mathrm{~N}_{7} \mathrm{O}_{3}\right](\mathrm{M}=\mathrm{Y}, \mathrm{Pr}, \mathrm{Nd}, \mathrm{Sm}, \mathrm{Eu}, \mathrm{Gd}, \mathrm{Tb}, \mathrm{Dy}, \mathrm{Ho}, \mathrm{Er})$, which we consider as a result of kinetic control. Synthesis with heating up to $100{ }^{\circ} \mathrm{C}$ yields thermodynamically more stable $\left[\mathrm{M}\left(\mathrm{H}_{2} \mathrm{O}\right)_{4} \mathrm{C}_{6} \mathrm{~N}_{7} \mathrm{O}_{3}\right]_{\mathrm{n}} \cdot \mathrm{nH}_{2} \mathrm{O}(\mathrm{M}=\mathrm{Y}, \mathrm{Ho}, \mathrm{Er}, \mathrm{Tm}$, $\mathrm{Yb}, \mathrm{Lu})$ and $\left[\mathrm{M}\left(\mathrm{H}_{2} \mathrm{O}\right)_{5} \mathrm{C}_{6} \mathrm{~N}_{7} \mathrm{O}_{3}\right]_{\mathrm{n}}(\mathrm{M}=\mathrm{Pr}, \mathrm{Nd})$. Structures of erbium cyamelurates (Fig. 1) and neodymium cyamelurate were solved using data of the powder XRD.

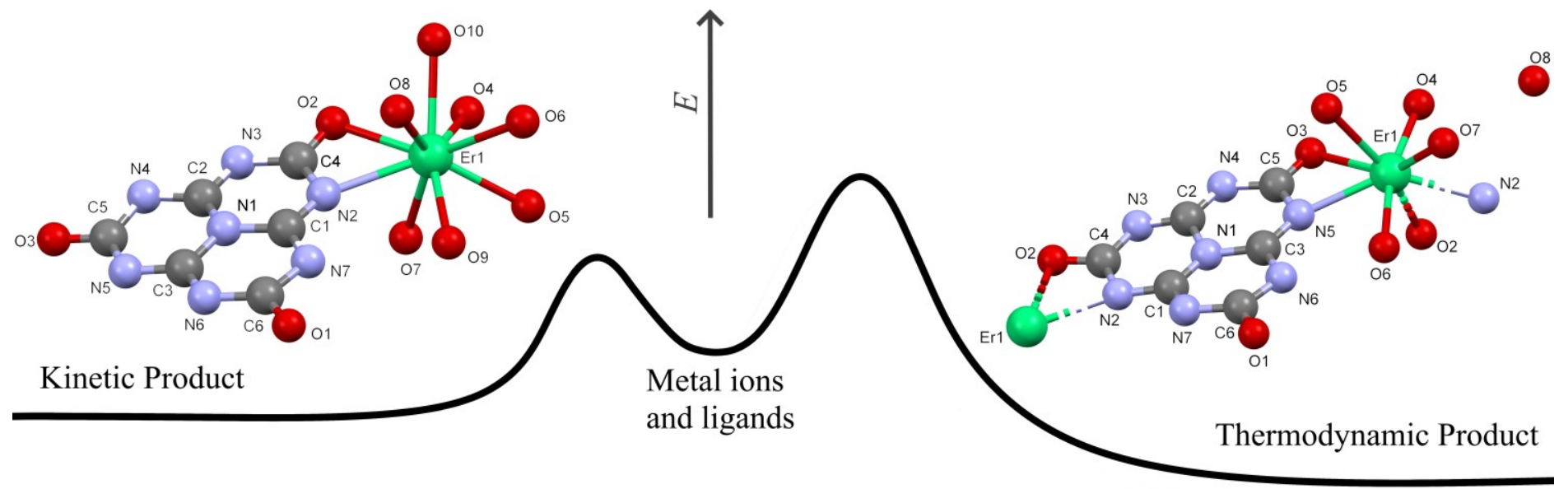

Figure 1. Reaction pathway in formation of kinetic and thermodynamic product and structures of erbium cyamelurate, obtained at room temperature (left) and at $100{ }^{\circ} \mathrm{C}$ (right). Hydrogens are not shown.

Thermodynamic products have denser structures compared to kinetic products. In synthesized at increased temperature erbium and neodymium cyamelurates polymeric chains exist due to the fact that the cyamelurate anion acts as a bridging ligand (Fig.1, right). Kinetically trapped erbium cyamelurate, in contrast, consists of individual complex molecules $\left[\operatorname{Er}\left(\mathrm{H}_{2} \mathrm{O}_{7} \mathrm{C}_{6} \mathrm{~N}_{7} \mathrm{O}_{3}\right]\right.$ (Fig.1, left). Probably, steric difficulties caused a decrease in the coordination number of erbium from 9 to 8 in the thermodynamic product. The coordination number of neodymium remains equal to 9 in both types of compounds.

The statement that the most stable product also can form the fastest, indicating that the kinetic and the thermodynamic product is one and the same [4], is confirmed by synthesized at elevated temperatures $\mathrm{Sm}, \mathrm{Eu}, \mathrm{Gd}, \mathrm{Tb}$, Dy cyamelurates with a similar structure as in the case of products obtained at room temperature.

[1] Ohtsu, H., \& Kawano, M. (2017). Chem. Commun. 53, 8818.

[2] Yan, Y., Huang, J. \& Tang, B. Z. (2016). Chem. Commun. 52, 11870.

[3] Marti-Rujas, J. \& Kawano, M. (2013). Acc. Chem. Res. 46, 493.

[4] Ji, Q., Lirag, R. C. \& Miljanic, O. S. (2014). Chem. Soc. Rev . 43, 1873.

Keywords: cyamelurates; crystal structure; kinetic control; thermodynamic control

This work is supported by grant 20-08-00097 from the Russian Foundation for Basic Research.

Acta Cryst. (2021), A77, C729 